\title{
Developing Framework to Test Driving Performance at Left-Turn Movement with In-Vehicle Advance Collision Warning Message
}

\author{
Mahreen Nabi, Fengxiang Qiao, Boya You, Lei Yu \\ Department of Transportation Studies, College of Science, Engineering, \& Technology, Texas Southern \\ University, Houston, Texas, USA \\ Email: labeeba4704@gmail.com, qiao_fg@tsu.edu, boya.you1@gmail.com,yu_Ix@tsu.edu
}

Received 6 January 2015; accepted 26 January 2016; published 29 January 2016

Copyright (C 2016 by authors and Scientific Research Publishing Inc.

This work is licensed under the Creative Commons Attribution International License (CC BY). http://creativecommons.org/licenses/by/4.0/

(c) (i) Open Access

\begin{abstract}
Left-turning traffic without a protected left-turn signal is one of the major safety concerns at urban intersections. Though an average of only $10 \%-15 \%$ of all approaching traffic turns left, significantly a large proportion of left-turn crashes occur involving $21 \%$ of all intersection fatal crashes. Where traditional safety countermeasures of signal timing-phasing and use of flashing yellow light have reportedly failed to significantly reduce the rate of crashes, an in-vehicle advance collision warning message can be helpful to reduce left-turn collisions at intersections. In this study, an in-vehicle audio warning application has been designed by providing two safety warning messages (Advance Warning Message and Safe Left-turn Maneuver Message) under the vehicle to vehicle (V2V) communication system, which is triggered based on the acceptable gaps of oncoming opposing vehicles for a safe left-turn. A driving simulator test has been conducted with 30 participants to investigate the impacts of warning messages on performance measures such as speed and acceleration profiles, collision records, brake reaction distance, and intersection clearance time. Statistical results showed that with the help of these messages, all participants were able to reduce speeds and accelerations and chose suitable gaps without potential conflicts. Moreover, the results of questionnaire analysis provide a positive acceptability especially for the Safe Left-turn Maneuver Message. Based on the performance measurements, this type of safety warning messages can be recommended for possible real-road tests for practical applications.
\end{abstract}

\section{Keywords}

Left-Turn Permissive Phase, Offset, Collision Warning System, Intelligent Transportation System, Intersection Safet 


\section{Introduction}

Engineers and researchers have always been developing innovative means of traffic control to increase the capacity of urban traffic system and to reduce the travel time, vehicular collisions, and emissions. To reach an optimal performance, a lot of studies have been conducted on geometric design, construction, maintenance, and safety strategies. However, road transportations related human fatalities, injuries, and property losses still have always been affecting the functionality of traffic flow operations. Motor vehicle crashes are one of the leading causes of death at roadway intersections where a number of activities such as turning left, crossing over, and turning right take place [1]. According to the National Highway Traffic Safety Administration's (NHTSA) Fatality Analysis Reporting System's (FARS) report, the numbers of fatalities at the intersections were 8851 and 8598 for 2012 and 2013 respectively [2]. Though the numbers of fatalities have been reduced by $2.9 \%$ from previous year, almost $36 \%$ - $40 \%$ of all fatal motor vehicle crashes still occur at the intersections every year. One of the most typical crash scenarios among them is Left Turn Across Path-Opposite Direction (LTAP/OD), involving 289,570 of fatalities and injuries annually [3] [4].

With the increase in traffic volume, the gaps between two oncoming vehicles became smaller than before which reduced the chances of safe left-turn and increased the queue length with longer waiting time for left-turn traffic. To alleviate this situation, signal phasing has been designed to provide a protected left-turn phase for part of the signal cycle following by a permitted phase [5]. This resulted Protected-Permitted Left Turn (PPLT) has shown the increased left turn capacity and reduced delay at intersections. According to a study of before-after crash analysis, the new modification from permitted phasing to protected-permitted phase reduced $14 \%$ of leftturn crashes [6]. Another study on 197 four-legged signalized intersections in Florida concluded that the frequency of left turn crashes at protected-permitted treatment is much higher than protected only action [7]. So in both cases, it can be stated that driver's driving behavior is more likely driven by their own judgments rather than the regulations while the signal is at permitted phase.

A lot of models have been developed on driver's tendency of accepting and rejecting gaps between two opposite oncoming vehicles that directly affect the crash severity. Some studies showed that the gap acceptance decisions of drivers are more related to the speed and distance between two successive vehicles [8] and some are related to time-to-arrival of opposing vehicles [9]. However, the investigations on the effect of gap acceptances on individual driving styles are relatively underexplored. The cause of these crashes at the Left Turn Across Path (LTAP)/Opposite Direction (OP, Right-of-way Traffic) can be summarized in some basic categories [4]. The major causes include: (1) human error, in which a driver becomes unable to judge the speed and safe time gaps of oncoming vehicles especially due to the obstructed view, and (2) geometrical design, in which a driver failed to perceive the approaching oncoming vehicles. The other factors are: weather conditions, age, gender, time of day, size of vehicles etc. [10]-[12].

Conventional traffic regulations and safety countermeasures mainly include static traffic control signs and traffic signal timing, which may not be sufficient to prevent crashes at left-turn movement. Moreover, one of the potential problems for left-turn traffic is sight distance obstruction due to the lack of offset or proper designed median, which may lead to a probable collision by confusing drivers to identify acceptable gaps [13]. Even as a solution of installing offset left-turn lanes, drivers may initially be confused by the change in traffic patterns, which may require additional safety countermeasures, such as advanced guide signings, pavement markings, and a longer installation and construction period [14]. Moreover, one of the major causes of sight obstruction and fatal crashes is the placement of a work zone nearby an intersection and also the atmospheric ambience contribute on drivers inadequate surveillances, especially during the night time [15]. According to the Motor Vehicle Crash Data, 7577 fatal crashes have occurred at the intersections due to the darkness [16].

With the advent of Intelligent Transportation System (ITS) technologies, various wireless connected vehicle communication systems have been proposed to enhance the safety in different conflicting areas, such as at unsignalized STOP sign intersection [17], signalized intersection with sun glare disturbance [18], at work zones [19]-[23], car following [24], and so on. The ITS technologies, including 5.9 GHz Dedicated Short-range Communications (DSRC) technologies, Wi-Fi, and Bluetooth, could build up the proposed systems to provide drivers with a visual or/and an audio advance collision warning messages. The application of these ITS technologies in the conflicting areas was promising. A recent study showed that an audio collision warning system could reduce the number of intersection crashes by $40 \%$ - 50\% through shortening driver's reaction time [25]. Another study by comparative analysis showed that a Smartphone based audio warning application using a female voice rec- 
ognition has more effective impact on altering driving behavior than male voice warning [26]. However, the potentiality of a Vehicle-to-Vehicle (V2V) based collision warning message for left-turn safety has been underinvestigated. In this regard, a properly designed collision warning message might mitigate the LTAP/OD crashes by detecting all approaching vehicles, measuring their speeds and acceleration rates, and giving two designed audio warning messages (female voice) would warn drivers and instruct them to start the left turn maneuver when a safe departure was calculated.

\section{Research Objectives}

The objective of this paper is to design and test the advance collision warning message to improve intersection safety for left-turn movement by assisting drivers to make safer turning decisions. Moreover, this paper will investigate the effectiveness of the in-vehicle warning messages on driving behaviors at a sub-urban signalized intersection, designed in a virtual environment with a driving simulator. In addition, it will also identify the available new wireless communication technology and discuss the potentiality in the reduction of vehicular collisions.

\section{Existing Strategies on Improving Left-Turn Safety}

Various safety strategies have been proposed which are associated with traffic signal, roadway design and advanced technology for left-turn movement. As a signal phasing aid, Flashing Yellow Arrow (FYA) signal indication has been adopted in 2009 Manual on Uniform Traffic Control Devices (MUTCD). Perhaps, more research is needed on designing effective indication sequences for FYA for desired communication with road users [27]. Many vehicle manufacturer companies have featured modern technologies built in vehicles for various collision warning such as-Forward Collision Warning (FCW), Lane Departure Warning (LDW), Blind Spot Warning (BSW), etc. In a recent study by Honda Research Institute, a left-turn aid has been developed by displaying 3s projected path of oncoming vehicle with a 3D Head-Up Display [28].

In sensor based collision warning system, the pair of sensors or laser detectors are installed on the left or right front corner of the host vehicle, which can detect cross-traffic vehicles and calculate their speed and time-tocollision [29]-[31]. The infrastructure based warning systems are basically a communication network between On-Board Equipment (OBE) and Road-Side Unit (RSU), which integrated with signal timing [32]. But for the left turn it is quite difficult, as in U.S.A most of the left-turn signals are at actuated phasing, which might need additional mechanisms. However, either some of these researches have some limitations or some of them are at preliminary observation stage.

Though all of these studies have been conducted to develop innovative safety measures, still studies on the application of V2V technology based countermeasures need more developments for left-turn safety. A recent study by NHTSA has predicted that successful application of this technology potentially address $79 \%$ of all vehicle target crashes (4,409,000 by police report) and could save 1083 lives and prevent 592,000 crashes annually at left-turn and intersection movements [33] [34]. In this regard, V2V based warning messages can be a suitable aid to enhance safety for left-turn traffic at the intersections. With the connected vehicle technology, two vehicles can communicate with each other and notify themselves by audio-visual warning, seat vibration, etc. depending on the necessity [35]. So, this technology has the potentiality to be used for the left-turn advance collision warning message suggested in this paper.

\section{Proposed In-Vehicle Warning Messages}

In this paper, the perceptual system architecture of the proposed audio in-vehicle advanced warning message have been designed by detecting the vehicles in opposite direction within a certain range, in which a driver can make a safe turn excluding the chances of probable conflicts. An on board DSRC equipped device can detect, transmit and receive safety information such as speed, acceleration, heading via wireless signals with other cars within a secure communication. A GPS equipped Smartphone can provide instantaneous geo-location information and share with the DSRC device for a successful transmission. The warning system in this study comprises of two messages.

(1) Advance Warning Message, which is to alert drivers, who are approaching the targeted intersection about the presence of opposite through traffic (Right-of-way Traffic) under the detection range. 
(2) Safe Left-turn Maneuver Message, which is to instruct drivers to make the turn as there is a safe gap between two vehicles in opposite direction. Figure 1 demonstrates a basic understanding of the test plan of this paper.

The whole design framework consists of a secure wireless network, which can be developed via Smartphone, DSRC equipped on-board sensors, etc. with the communications to ITS management center's database. Due to the safety concerns and technical limitations, the framework setting was deployed in a virtual environment of a driving simulator rather than a real road testing. The University of Michigan Transportation Research Institute has launched a pilot program at Ann Arbor, where the vehicles and the infrastructures are integrated with the supportive technology to test the reliability and technical equity of V2V effectiveness depending on driver's response [36]. This might be a possible scope to test the left-turn aid in real road environment.

\section{Scenario Design at Driving Simulator}

\subsection{Driving Simulator}

The use of driving simulator for research has been considerably increased to study safety and recognize the imminent motor vehicle crashes. A simulator can replicates scenarios, including the physical and environmental elements of roadway design in a visual way to evaluate driving performance [37]. A full-motion driving simulator has been employed in this experiment to test the V2V communication network and evaluate the suitable location for warning messages to gain successful results on driver's reaction time and turning maneuver. This simulator features a high performance and fully-integrated multi-channel audio-visual system with $240^{\circ}$ wraparound displays. As a real automobile, it has driving seat, windshield, side mirror, steering, indicators, dashboard, breaking and accelerating system etc.

\subsection{Test Participants}

A total number of 30 participants were recruited from Houston, Texas. All participants were required a valid driving license to operate the driving simulator. Following the demographic distribution by the 2010 census of Houston, 19 participants were under the age group of 25 - 65 years, 10 participants were under 25 age group and 1 was over 65 . 33\% of the participants were female. All participants include 10 high school and undergraduate students, 12 graduate students, 2 Ph.D. students, and 4 job holders.

\subsection{Traffic Scenarios and Audio Warning Messages Design}

The scenarios were developed in driving simulator using the software Hyper Drive following three steps-1) Choosing the tile according to the test roadway layout, 2) Positioning the static and dynamic entities (speed limit

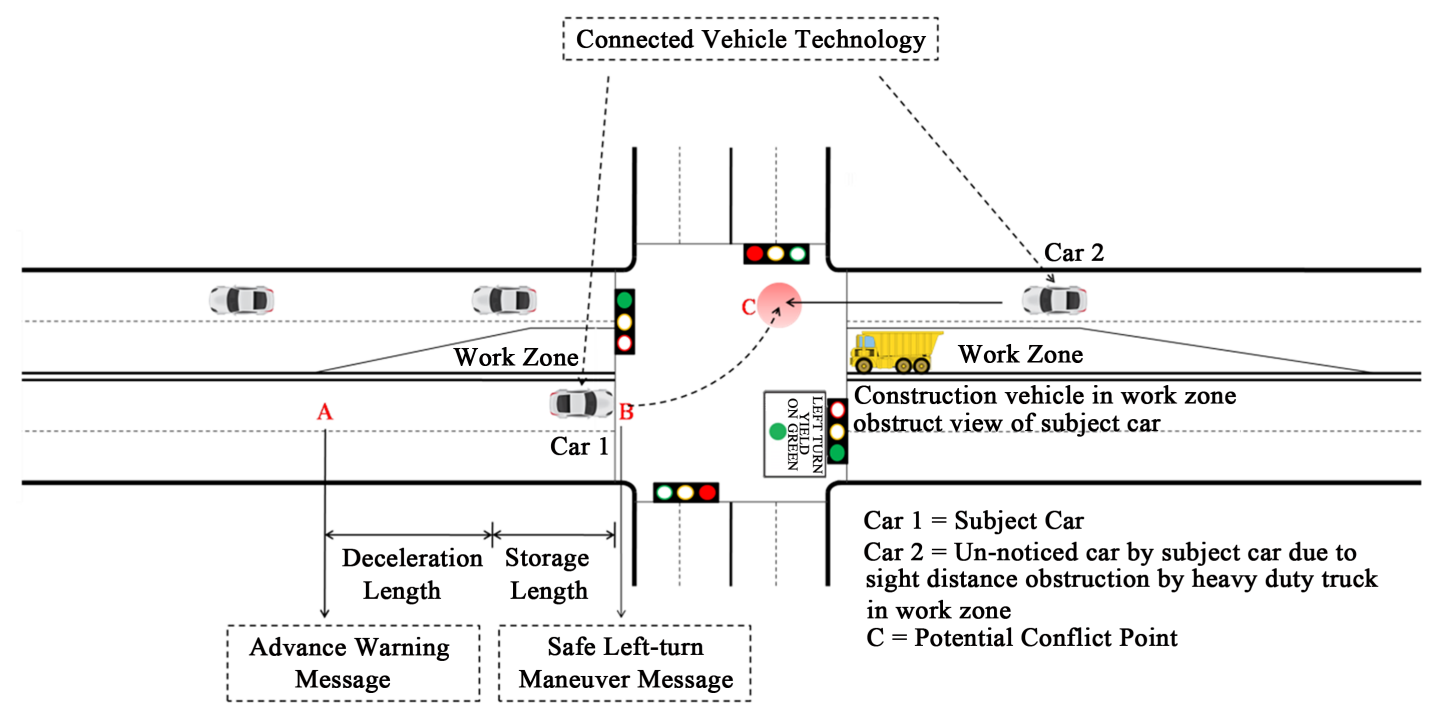

Figure 1. Basic framework of in-vehicle advance collision warning message. 
signs, traffic signals and signs, and other motor vehicles), and 3) Scripting and setting up the location triggers. The scenarios were designed according to the Manual on Traffic Control Device (MUTCD) specifications [38]. The scenario has a work zone in the opposite lane, which was designed according to Chapter 6 (Fig. $6 \mathrm{H}-23$ ) Left-Hand lane closure on the far side of the intersection. Figure 2(a) shows the intersection design in Hyper Drive and Figure 2(b) shows the view from subject car during the driving test.

A sub-urban intersection with two lanes in each direction with no offset tile has been chosen as a suitable solution. The driving test includes four scenarios and in each scenario drivers were asked to make a left turn at the intersection where the signal is at permitted phase (Yield on Green). As the participant approached the intersection, a series of oncoming vehicles with pre-designed speed enter the intersection from the opposite direction at an increasing time gap intervals from 1 to 8 seconds. Due to the presence of a big construction vehicle in the work zone, the subject driver could not see those approaching vehicles clearly. This affects their judgments on gap acceptances. The sequence of the scenarios was followed by a pre-designed table in order to avoid the unnecessary guesses by the participants. The drivers were instructed before starting each scenario according to the sequence.

The most important part in scenario design is the placement of location triggers, which could convey in-vehicle messages. As soon as the subject vehicle reached into the designed radius of the triggers, the encryptions would be activated and the driver will receive two voice-warning messages. Both were female voices that were generated from an online Text to Speech (MP3) converter LISTEN [39]. All participants were asked to drive a practice session before the test to make them comfortable with the automobile cabin and also to make them be accustomed with the left turn radius. After the test, each participant filled up a post questionnaire survey regarding their simulator driving experiences. The whole process including the post-questionnaire took approximately 12 - 15 minutes each.

In the scenarios, the dimension of the intersection from stop line to opposite stop line is $42 \mathrm{~m} \times 42 \mathrm{~m}$. The posted speed limit for subject vehicle is $35 \mathrm{mph}\left(56.3 \mathrm{~km} \cdot \mathrm{h}^{-1}\right.$ or $\left.15.65 \mathrm{~m} \cdot \mathrm{s}^{-1}\right)$ and the road width is $3.6 \mathrm{~m}$. According to MUTCD Chapter 6, the speed limit for opposite through vehicle is $25 \mathrm{mph}\left(40.23 \mathrm{~km} \cdot \mathrm{h}^{-1}\right.$ or 11.18 $\mathrm{m} \cdot \mathrm{s}^{-1}$ for temporary work zone availability) [38]. Figure 3 illustrates a typical layout of intersection considering the left lane as left-turn lane and consists of four-lane roadway, a work zone, and a PPLT signal phasing (protected-permitted left-turn) designed in the simulator. Four scenarios with all this fixed specifications have been designed. Table 1 shows the detail information on scenarios and audio messages.

\section{Test Procedure}

Two important distances were determined in this study: 1) Advance warning message distance $\left(D_{a}\right)$ and 2) Safe left-turn maneuver message distance $\left(D_{s}\right)$.

1) Advance Warning Message Distance $\left(D_{a}\right)$

In Figure 4, location $A$ is the trigger point of advanced warning message. $D_{1}$ and $D_{2}$ represent the distances of roadway static signs from the stop line of the intersection.

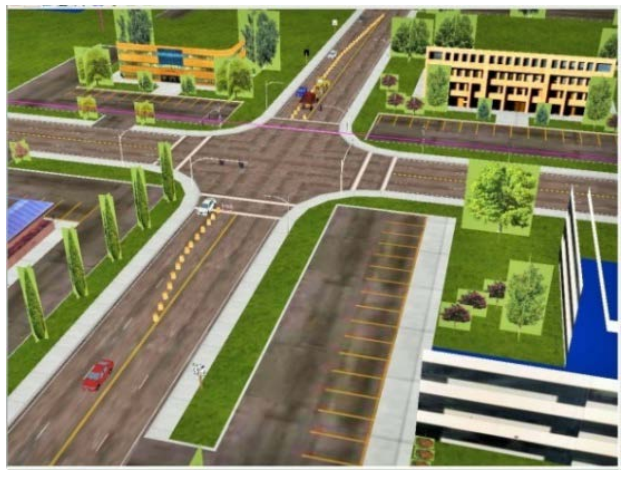

(a)

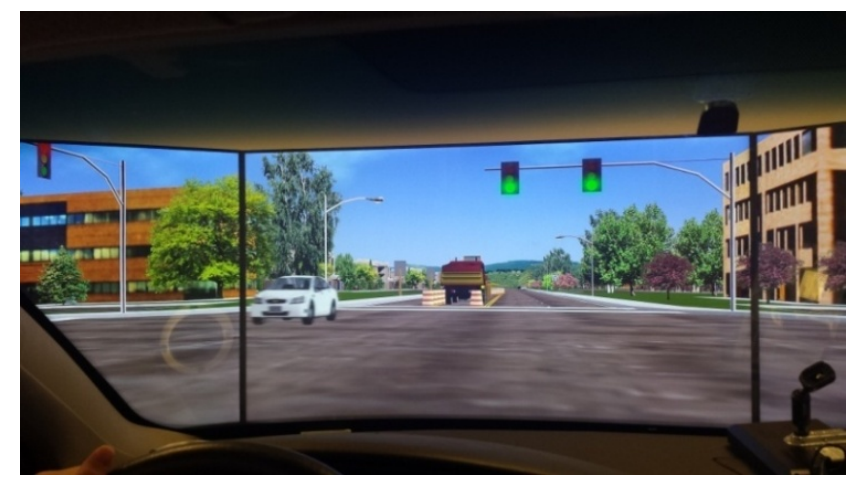

(b)

Figure 2. Test scenarios design in simulator. (a) Intersection design in Hyper Drive; (b) Driving test session at the intersection waiting for left-turn. 


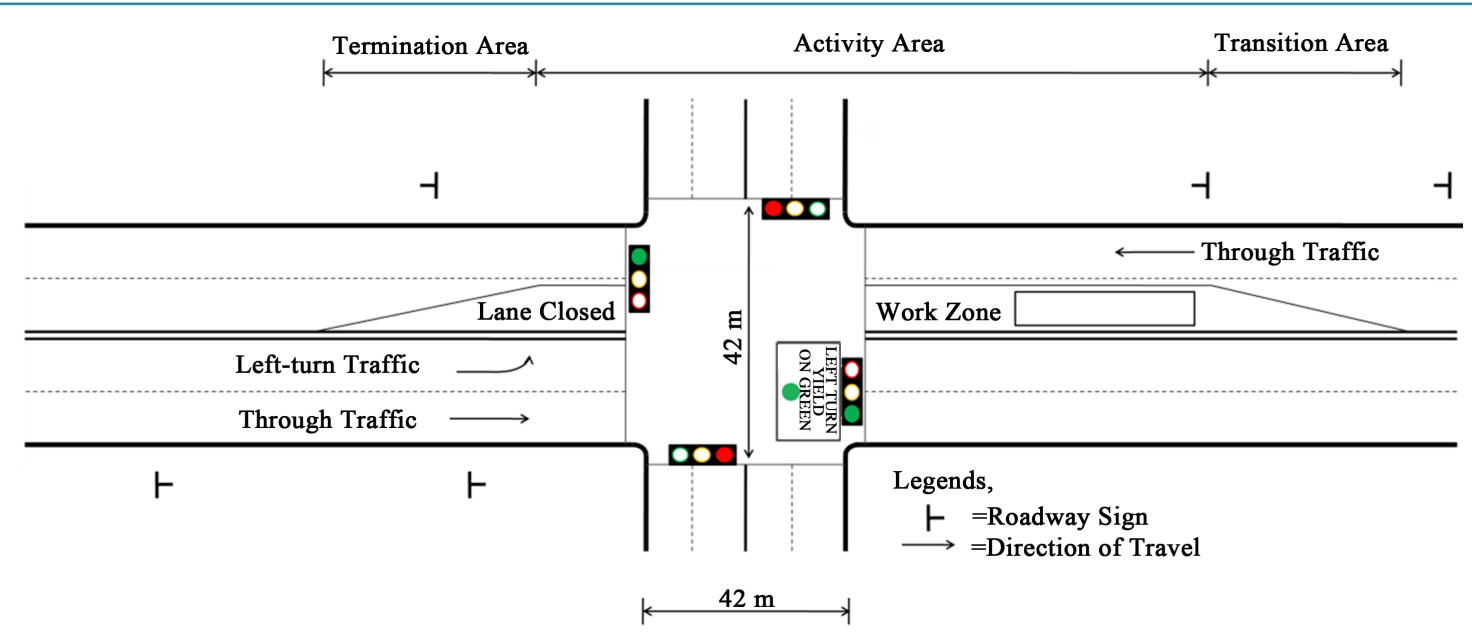

Figure 3. Typical layout of intersection design used in this research.

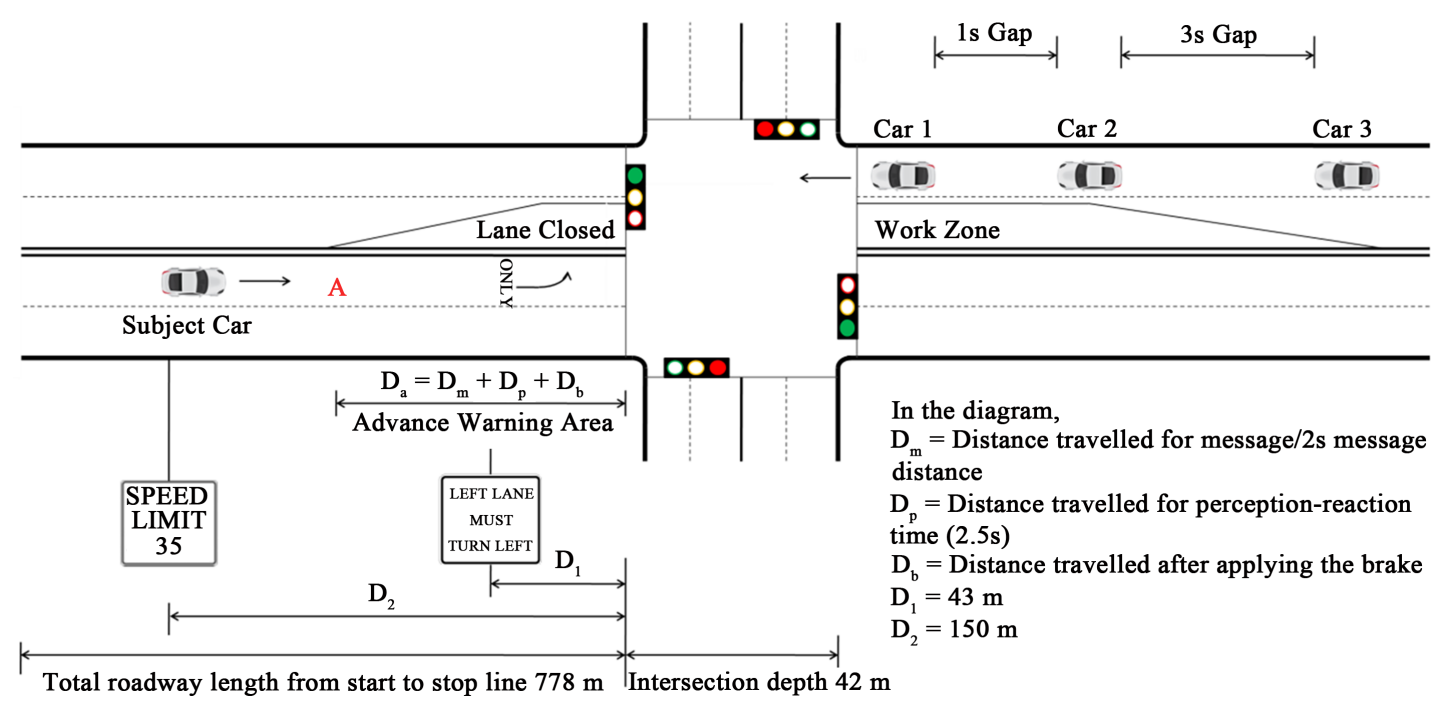

Figure 4. Placement of roadway signs and advance warning message for simulator test.

Table 1. Description and sequence of four scenarios and two messages.

\begin{tabular}{|c|c|c|c|}
\hline \multirow{2}{*}{ Time of day } & \multicolumn{3}{|c|}{ Description and sequence of the scenarios and message options } \\
\hline & Scenario type & Message option & Content of messages (female voice) \\
\hline Day-time & $\begin{array}{c}\text { Baseline scenario } \\
\text { Warning message scenario }\end{array}$ & $\begin{array}{c}\text { No message } \\
\text { Two audio messages }\end{array}$ & $\begin{array}{l}\text { None } \\
\text { A. "Yield. Wait for further instructions" } \\
(2 \mathrm{~s}) \\
\text { B. "Make a turn" }(1 \mathrm{~s})\end{array}$ \\
\hline Night-time & $\begin{array}{c}\text { Baseline scenario } \\
\text { Warning message scenario }\end{array}$ & $\begin{array}{c}\text { No message } \\
\text { Two audio messages }\end{array}$ & $\begin{array}{l}\text { None } \\
\text { A. "Yield. Wait for further instructions" } \\
(2 \mathrm{~s}) \\
\text { B. "Make a turn" }(1 \mathrm{~s})\end{array}$ \\
\hline
\end{tabular}

According to the table of Stopping Sight Distance from Section 3 of Roadway Design Manual of TxDOT, the brake reaction distance is predicted on a time of $2.5 \mathrm{~s}$ (Driver's Perception-reaction Time) and deceleration rate is $11.2 \mathrm{fts}^{-2}$ or $3.413 \mathrm{~ms}^{-2}$ [40]. When the design speed is $35 \mathrm{mph}$ or $15.65 \mathrm{~ms}^{-1}$, Brake reaction distance is $39 \mathrm{~m}$ and the breaking distance is $35.85 \sim 36 \mathrm{~m}$ on level. The total stopping sight distance would be $75 \mathrm{~m}$. 
When a driver receives an audio message, he will take a certain amount of time to apply the brake. The whole stopping time undertakes driver's reaction time, deceleration time and message time to stop before the stop line and to ensure that there is no vehicle in the intersection for crossing. The advance warning message lasts for $2 \mathrm{~s}$. So, $2 \mathrm{~s}$ message distance is the distance travelled during driver received the message.

- Brake Reaction Distance $\left(D_{p}\right)=2.5 \mathrm{~s} \times 15.65 \mathrm{~ms}^{-1}=39 \mathrm{~m}$ (Speed Limit $=15.65 \mathrm{~ms}^{-1}$ )

- Braking Distance $\left(D_{b}\right)=v^{2} / 2 \mu g=35.85 \sim 36 \mathrm{~m}$; Where, $\mu=$ Co-efficient of friction, for concrete $\mu=1$ and g $=$ Deceleration Rate [41] [42]

- 2 s Message Distance $\left(\mathrm{D}_{\mathrm{m}}\right)=2 \times 16.09=32.18 \mathrm{~m}$

So, Advance Warning Message Distance $\left(\mathrm{D}_{\mathrm{a}}\right)=$ Stopping Sight Distance (Brake Reaction Distance+ Braking Distance) +2 s Message Distance $=39+36+32.18=107.18 \mathrm{~m} \sim 107 \mathrm{~m}$

2) Safe Left-turn Maneuver Message Distance $\left(D_{s}\right)$

In Figure 5, location B is the point where the driver of subject vehicle receives the safe left-turn maneuver massage when there is safe gap between two vehicles in opposite direction.

So, Safe Left-turn Maneuver Message Distance $\left(D_{s}\right)=$ Brake reaction distance $\left(D_{p}\right)+1$ s message distance $\left(D_{m}\right)+4$ s gap distance between car 3 and car $4=39+16.09+64.36=119.45 \sim 120 \mathrm{~m}$.

While receiving the advance warning message, the driver would decelerate smoothly and slow down before the stop line and wait for further instructions as the message conveys. After car 3 left the intersection and car 4 is at a safe gap distance, safe left-turn maneuver message will be delivered to make a safe turn before car 4 reaches the intersection. An observational study in the field found that $85 \%$ of the passenger vehicles require max. 3.5 s to execute a left turn, which is less than the safe gap time, designed in this study [31]. In the simulator test, participants drove in the baseline scenarios without any audio instructions. In most of the cases, participants felt it difficult to watch opposite through vehicles due to the view obstruction by work zone and they drove into the intersection to watch ahead and then made the turn. During the audio messages scenarios, participants stopped before the stop line leaving the intersection clear and then the second message helped them to make the turn safely. The purpose of this study is, if a driver failed to see an incoming vehicle from opposite direction, through this technology driver can get help to understand that there will be a vehicle arriving within few seconds, which might involve into an unexpected collision.

\section{Results and Discussions}

The simulator-based driving tests of 30 participants in different scenarios were analyzed based on recorded data provided by Hyper Drive software. The data present the indexes of $1 / 60 \mathrm{~s}(1 \mathrm{~s}=60$ records) including vehicles geo-location, speed, acceleration rate, collision information, steering angle, etc. By using the interpolation function in MATLAB, the evenly distributed records along the time axis were converted into evenly distributed records along the space axis (meter by meter data sets). In this research, some basic indexes have been chosen to measure the performances of the warning messages, such as speed profiles, acceleration rate, brake reaction dis-

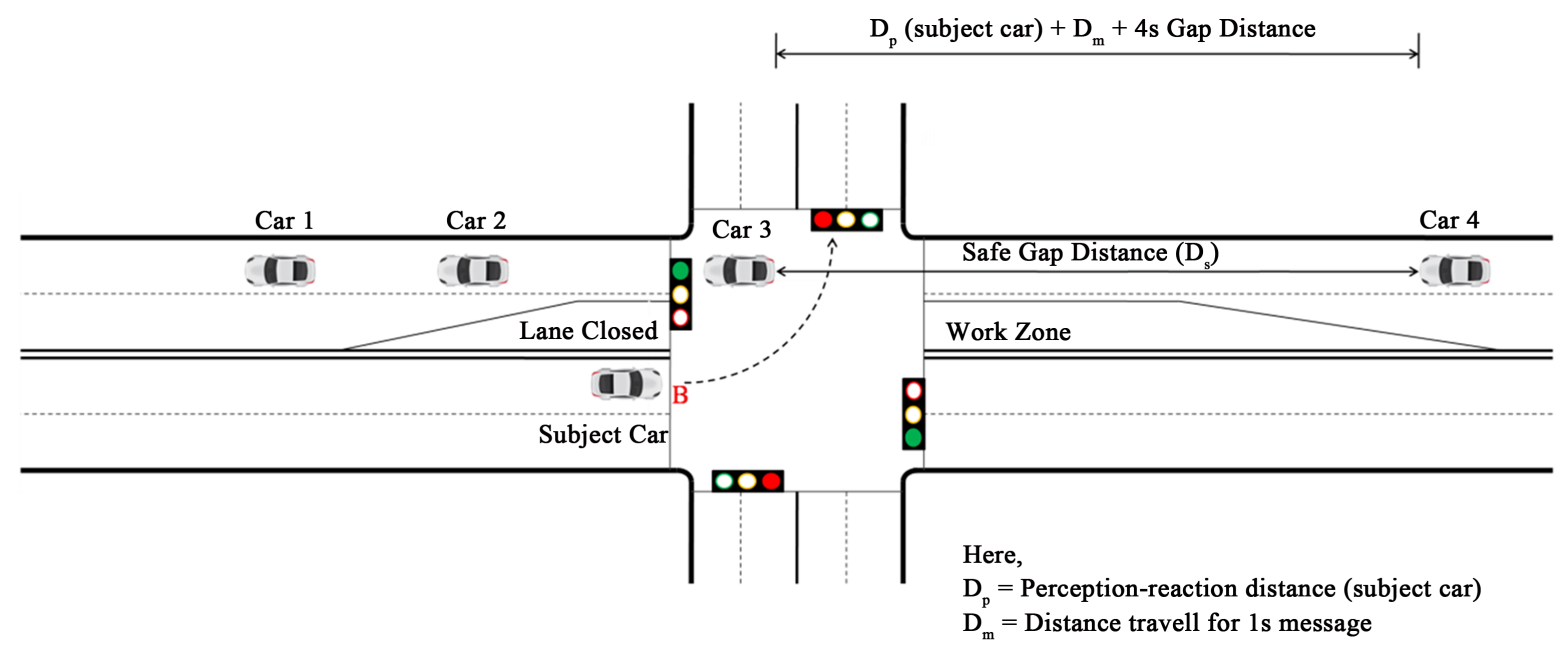

Figure 5. Placement of safe left-turn maneuver message for simulator test. 
tance, time required for left turn and collision observations. Later, a paired t test by SPSS software has been conducted to examine the significance of the results of driving test.

\subsection{Speed Profiles}

To compare the speed profiles for 30 participants, mean speeds have been calculated for four scenarios. The variations in speed curves represent driving behaviors for each scenario. The high value of mean speed and distance means that the vehicle entered the intersection with a high speed, which might be dangerous. Figure 6 shows that in the baseline scenarios, drivers enter the intersection (approximately $10 \mathrm{~m}$ inside, BC distance in Figure 6) with a comparatively higher speed (10 mph or $4.47 \mathrm{~ms}^{-1}$ higher) than the message scenarios. In the night-time baseline scenario, the mean value is higher than other scenarios, because driver's judgment of the distance of approaching intersection wasn't clear due to the darkness. With the help of warning messages, drivers were able to stop before the stop line with a reduced speed and waited for the suitable gaps. After the second audio message drivers smoothly accelerate and make the turn safely.

In the paired t-test, the statistical difference of mean speeds between baseline and audio warning scenario in daytime was significant with $p$-value $=1.0879 \times 10^{-4}$. Similarly, a significant statistical difference of mean speeds with a $p$-value $=0.001$ existed between the baseline scenario and audio warning message scenario at night-time. This significance at $95 \%$ of confidence level justify that the warning messages have a potential impact on speed profiles which affect driving behaviors.

\subsection{Impacts on Acceleration}

Acceleration or deceleration is one of the most important performance measures to analyze the safety issues while driving. In the real world, drivers usually achieve a certain speed limit and when there is some situation for braking, they take some reaction time to apply the brakes. In the baseline scenarios, when participants were approaching the intersection, most of them sharply decelerate close to the stop line when they found incoming opposite vehicles. Some of the participants haven't reduced their speed much and turn left with a potentiality of collision with car 3. Figure 7 demonstrates the mean acceleration distribution of 30 participants for four scenarios. In the baseline scenarios, the curve after the stop line has more than two peaks. That means they have applied brake several times due to the misjudgment of gaps within the intersection. In the message scenarios specially in the night time, drivers uniformly decelerate before the stop line when they got the first message (excluding reaction distance) and after the second message the curves show smooth acceleration for both times.

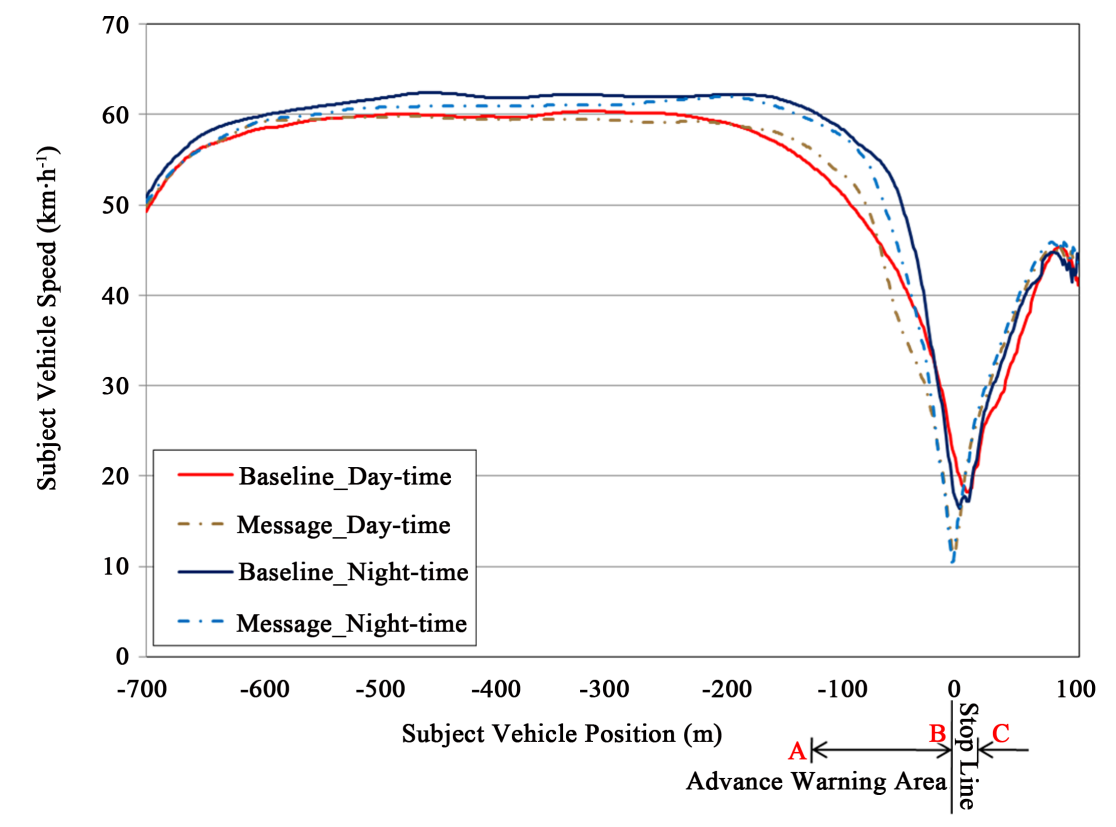

Figure 6. Comparison of mean speed of 30 participants for four scenarios. 


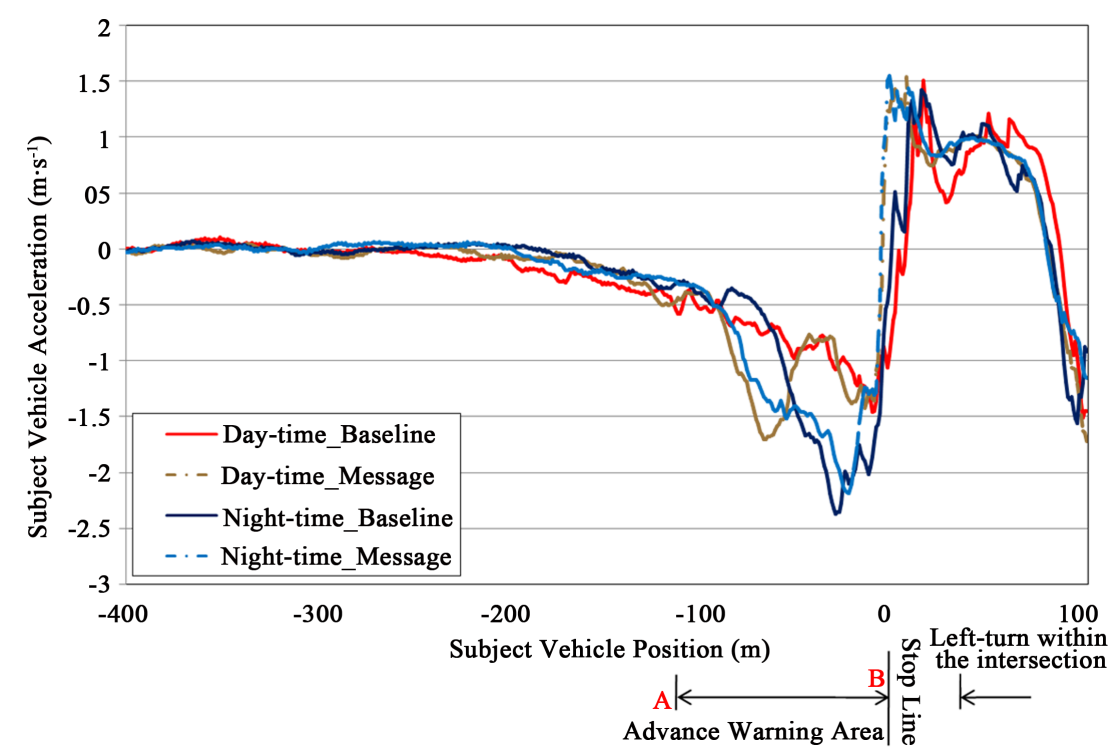

Figure 7. Comparison of mean acceleration of 30 participants for four scenarios.

The statistical difference between the baseline scenario and audio message scenario for day-time shows a significant value of $p<0.001$. With $95 \%$ confidence level, the result indicates that the message implication helped the drivers to drive smoothly within the intersection.

\subsection{Brake Reaction Distance for Advance Warning Message}

The brake reaction distance for the advance warning message shows the impact of reaction time on driving behaviors. In this research, the designed reaction time is $2.5 \mathrm{~s}$. The brake reaction time can be calculated based on the reaction distances (higher the distance lowers the chances of any potential collision). Brake Reaction Distance is the distance, which is traveled while the drivers get the warning and apply the brake. From the statistical observations of the acceleration graph we can calculate the reaction distances, when each participant released the acceleration before the stop line. Due to the upcoming intersection, all participants started to decelerate early, but with the message especially in night-time scenario, participants reacted promptly. That implicates that with the message participants get advance notification on upcoming situation if they failed to notice any intruding traffic due to any disruption. Figure 8 shows the mean brake reaction distance with the standard deviation for 30 participants. With the advance warning the brake reaction distance reduced to $19.27 \mathrm{~m}$ and $25.24 \mathrm{~m}$ respectively for day and night time.

With 95\% paired t-test, the statistical difference between the baseline scenarios and audio message scenarios for day-time and night-time showed a significant value of $p$-value $=3.43 \times 10^{-5}$ and $p$-value $=4.97 \times 10^{-4}$ respectively. With such confidence level, the result indicates that the message implication helped the drivers to react more efficiently for safer decisions.

\subsection{Impact of Safe Left-Turn Maneuver Message on Intersection Clearance}

The intersection clearance time mostly depends on the gap acceptances of the drivers. In the baseline scenarios, participants tried to turn in $3 \mathrm{~s}$ and $4 \mathrm{~s}$ gap within opposite vehicles and couldn't finish the turn as they perceived that the time is not enough for turning. In those cases, they drove within the intersection with a much higher speed and brake several times as they noticed opposite oncoming vehicles. This situation left an unsafe distance between two opposite vehicles. In the real world, intersection clearance is one of the most important countermeasures for safety. If a vehicle waits for a long time within the intersection without finding a suitable gap, it may lead to a hazardous situation with through traffic across path as the change in signal timing. Figure 9 shows the mean time to make the turn from left-lane stop line to across path stop line (total wait time before a driver make a left turn) with the standard deviation value of 30 participants. As per the chart, the mean value of time required for left-turn in the message scenarios reduced by $2.7 \mathrm{~s}$ and $2.1 \mathrm{~s}$ for day and night time respectively. 


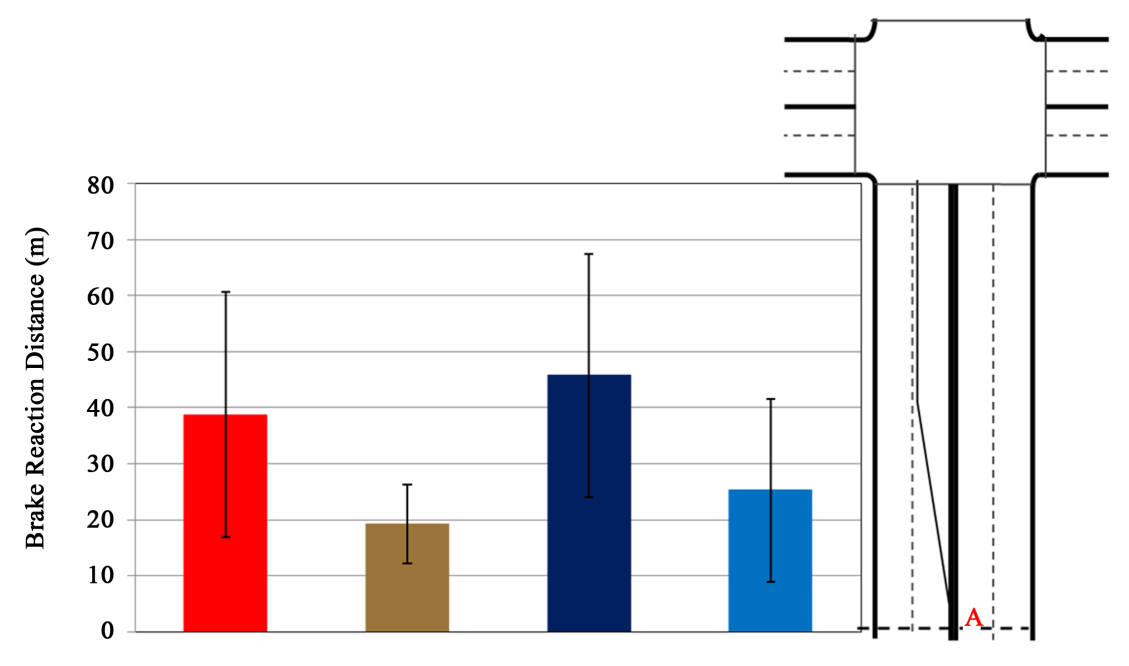

Day-time_BL Day-time_WM Night-time_BL Night-time_WM

$\mathrm{BRD}=38.76 \mathrm{~m} \mathrm{BRD}=19.27 \mathrm{~m} \quad \mathrm{BRD}=45.74 \mathrm{~m} \quad \mathrm{BRD}=25.24 \mathrm{~m}$

Figure 8. Brake reaction distances from participants performance on advance warning message.

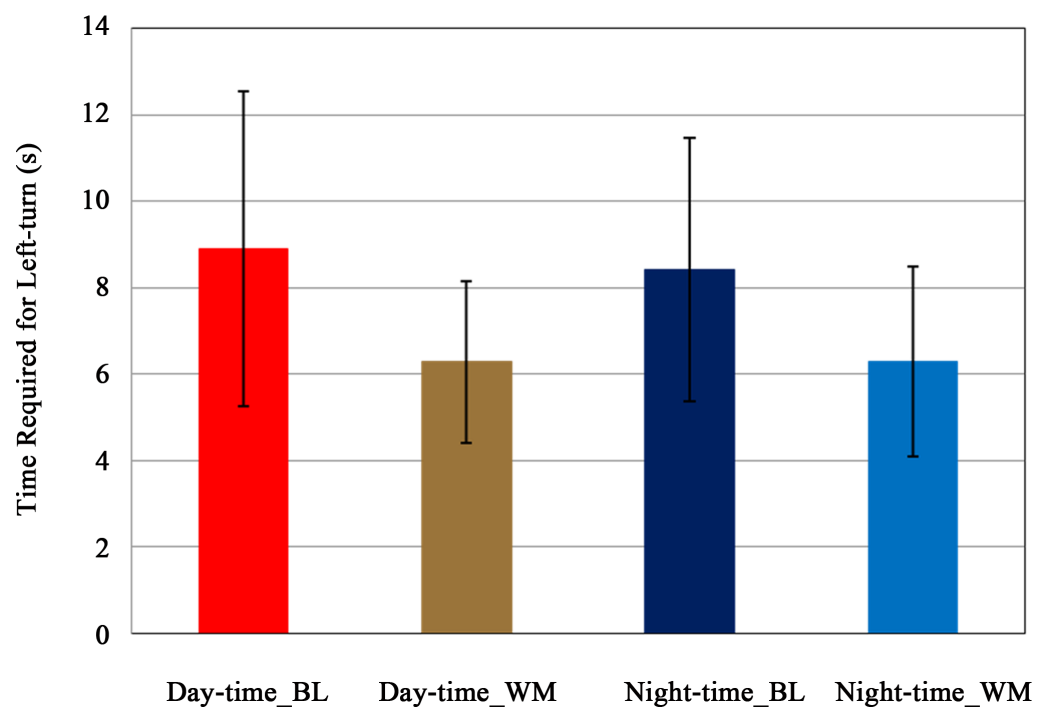

Figure 9. Comparison of mean value of time for making left-turn for 30 participants.

With 95\% paired t-test, the statistical difference between the baseline scenarios and audio message scenarios for day-time and night-time showed a significant value of $p<0.001$. So it can be implied that the message scenarios secure more safety in regard of clearing the intersection which provide a positive understanding.

\subsection{Collision Observations}

Table 2 demonstrates the collision observation results subtracted from the collision data and headway time and distances with opposite through vehicles.

It is found that, total twelve participants had a close distance with car 2 (headway time less than $3.5 \mathrm{~s}$ ), as they enter the intersection with moderately higher speed and decelerate abruptly with hard braking, which showed amateur driving skills. Moreover, total 15 participants had a critical distance with car 3 (headway time less than $3.5 \mathrm{~s}$ ) as they failed to notice it and as a result had to make a hard brake within the intersection. With the audio warning application, 30 participants were able to make a safe left turn and also maintained a secured headway 
Table 2. Collision observation from recorded data.

\begin{tabular}{ccccc}
\hline \multirow{2}{*}{ Time of day } & Collision observation & \\
\cline { 2 - 5 } & Scenario type & $\begin{array}{c}\text { No of collision } \\
\text { with Car 3 }\end{array}$ & $\begin{array}{c}\text { No of potential } \\
\text { collision with car 2 }\end{array}$ & $\begin{array}{c}\text { No of potential } \\
\text { collision with car 3 }\end{array}$ \\
\cline { 2 - 5 } Day-time & Baseline scenario & 3 & 4 & 7 \\
& Warning message scenario & 0 & 0 & 0 \\
Night-time & Baseline scenario & 4 & 8 & 8 \\
& Warning message scenario & 0 & 0 & 0 \\
\hline
\end{tabular}

distance with car 2, 3 and 4, which surely indicates that the audio warning had a positive impact on driving behavior.

\section{Questionnaire Survey}

Based on post-test questionnaire survey, 30 participants agreed that the audio messages helped them make a safe left-turn which is an indication of defensive driving. 21 participants (70\%) wanted to install this technology in their vehicle, where 9 people were indifferent of its usage. Moreover, $66 \%$ and $96 \%$ people for day-time and night-time respectively felt that the audio warning was extremely helpful.

During the test, 22 participants (73\%) successfully followed the instructions of the messages and felt that the warnings did not increase any additional work load, where 7 participants felt that it will take more time to get used to the warning messages. 80\% participants appreciated the Safe Left-turn Maneuver Message more than the Advanced Warning Message. They also mentioned that the message content were clear and user-friendly. The survey results provided a positive indication of participants on the usage of in-vehicle audio messages for intersection safety and to recognize the traffic situation earlier especially in an obstructed or invisible traffic situation.

\section{Conclusions}

In this paper, a perceptual framework of in-vehicle collision warning message as a left-turn driving aid has been outlined and deployed through a driving simulator test to enhance safety at the urban intersections. From the comparative statistical analysis, values of mean speed of 30 participants showed a significant impact on driving behavior depending on driver's reaction in the message scenarios. Moreover, the comparative analysis also showed that the ambience of night-time scenarios contribute to the effectiveness of performance measures, as most of the participants showed different driving pattern at night-time. In terms of mean acceleration, the baseline scenarios have more peaks in the curves especially after the delivery of Safe Left-turn Maneuver Message, which demonstrates that drivers accelerate and decelerate randomly as they were unsure on upcoming situations which cost more vehicular emissions.

With the impact of this particular warning message, most of them uniformly accelerate and make the turn safely. Most importantly, it had been observed that $80 \%$ of participants were able to make the turn in a short time than the baseline scenarios which contributed in reduction of travel time. In addition, the questionnaire survey and the collision analysis showed a promising possibility for this aid at left-turn movement. Considering the positive results and discussions of this experiment and utilizing the prospects and advantages of V2V technology, the designed audio warning would assist drivers to determine if a safe gap is available to execute the left-turn by providing messages depending on the availability of vehicles in opposite direction. To further investigate the potentiality of this type of technology, road test with a diverse demographic representation should be conducted to validate the operational impact of driving behavior with more performance measurement analysis in real environment.

\section{Acknowledgements}

The authors acknowledge that this research is supported in part by the United States Tier 1 University Transportation Center TranLIVE \#DTRT12GUTC17/ KLK900-SB-003, and the National Science Foundation (NSF) under grants \#1137732. The opinions, findings, and conclusions or recommendations expressed in this material are those of the author(s) and do not necessarily reflect the views of the funding agencies. 


\section{References}

[1] Choi, E. (2010) Crash Factors in Intersection-Related Crashes: An On-Scene Perspective. Report No. DOT HS 811366, National Highway Traffic Safety Administration (NHTSA), Washington DC.

[2] Traffic Safety Facts Research Note (2013) Motor Vehicle Crashes: Overview. Report No. DOT HS 812101. National Highway Traffic Safety Administration NHTSA’s National Center for Statistics and Analysis.

[3] Traffic Safety Facts (2013) A Compilation of Motor Vehicle Crash Data from the Fatality Analysis Reporting System and the General Estimates System, DOT HS 812139, U.S. National Highway Traffic Safety Administration NHTSA’s National Center for Statistics and Analysis. U.S. Department of Transportation Washington DC.

[4] Misener, J. (2010) Cooperative Intersection Collision Avoidance System (CICAS): Signalized Left Turn Assist and Traffic Signal Adaptation. Department of Transportation Studies, University of California, California PATH Research Report UCB-ITS-PRR-2010-20.

[5] Brehmer, C.L, Kacir, K.C., Noyce, D.A. and Manser, M.P. (2003) Evaluation of Traffic Signal Displays for Protected/ Permissive Left-Turn Control. Report No. 493, National Cooperative Highway Research Program, Transportation Research Board, Washington DC.

[6] Davis, G.A. and Mudgal, A. (2013) Field Study of Driver Behavior at Permitted Left-Turn Indications. Intelligent Transportation Systems Institute, Center for Transportation Studies University of Minnesota, CTS Project \#2012019, March 2013.

[7] Wang, X. and Abdel-Aty, M. (2008) Analysis of Left-Turn Crash Injury Severity by Conflicting Pattern Using Partial Proportional Odds Models. Journal of Accident Analysis and Prevention, 40, 1674-1682. http://dx.doi.org/10.1016/j.aap.2008.06.001

[8] Davis, G.A. and Swenson, T. (2004) Field Study of Gap Acceptance by Left-Turning Drivers. Transportation Research Record: Journal of the Transportation Research Board, 1899, 71-75. http://dx.doi.org/10.3141/1899-09

[9] Davis, G.A. and Mudgal, A. (2015) Gap Selection Behavior at Permitted Left-Turn Indications on an Urban Arterial. 94th Transportation Research Board Annual Meeting, Washington DC, 11-15 January 2015, No. 15-5415.

[10] Caird, J. and Hancock, P. (1994) The Perception of Arrival Time for Different Oncoming Vehicles Arriving at an Intersection. Journal of Ecological Psychology, 6, 83-109. http://dx.doi.org/10.1207/s15326969eco0602 1

[11] Campbell, J.L. and Graham, J. (2012) Human Factors Guidelines for Road Systems, Second Edition. Project 17-47, NCHRP Report 600, Transportation Research Board, Washington DC.

[12] Zhou, H., Lownes, N.E., Ivan, J.N., Gårder, P.E. and Ravishanker, N. (2015) Left-Turn Gap Acceptance Behavior of Elderly Drivers at Unsignalized Intersections. Journal of Transportation Safety \& Security, 7, 324-344. http://dx.doi.org/10.1080/19439962.2014.976689

[13] Amjadi, R. (2009) Safety Evaluation of Offset Improvements for Left-Turn Lanes. Publication No. FHWA-HRT-09036, The Federal Highway Administration (FHWA), US Department of Transportation, Washington DC.

[14] Troy, S. and Simpson, C. Offset Left-Turn Lanes. Report. North Carolina Department of Transportation. http://www.ctre.iastate.edu/educweb/expressway_intersections/NCHRP\%2015-30,\%20Offset\%20Left-Turn\%20Case\% 20Study.pdf

[15] Qiao, F., Jia, J., Yu, L., Li, Q. and Zhai, D. (2014) Drivers’ Smart Assistance System Based on Radio Frequency Identification Enhanced Safety and Reduced Emissions in Work Zones. Transportation Research Record: Journal of the Transportation Research Board, 2458, 37-46. http://dx.doi.org/10.3141/2458-05

[16] FARS-Transportation Injury Mapping System (TIMS). Fatality Analysis Reporting System Encyclopedia. http://www-fars.nhtsa.dot.gov/Crashes/CrashesTime.aspx

[17] Li, Q., Qiao, F., Wang, X. and Yu, L. (2016) Drivers Smart Advisory System Improves Driving Performance at STOP Sign Intersections. Journal of Traffic and Transportation Engineering (English Edition), in Press.

[18] Li, Q. and Qiao, F. (2014) How Drivers’ Smart Advisory System Improves Driving Performance? A Simulator Imitation of Wireless Warning on Traffic Signal under Sun Glare. LAMBERT Academic Publishing, Saarbrücken.

[19] Qiao, F., Li, Q. and Yu, L. (2014) Testing Impacts of Work Zone X2V Communication System on Safety and Air Quality in Driving Simulator. Proceedings of the 21st ITS World Congress, Detroit, 7-11 September 2014, 1-11.

[20] Li, Q., Qiao, F., Wang, X. and Yu, L. (2013) Impacts of P2V Wireless Communication on Safety and Environment in Work Zones through Driving Simulator Tests. Proceedings of the 26th Annual Conference of the International Chinese Transportation Professionals Association (ICTPA), Tampa, 24-26 May 2013, Paper \#26-179.

[21] Li, Q., Qiao, F. and Yu, L. (2015) Fuzzy Lane-Changing Models with Socio-Demographics and Vehicle-to-Infrastructure System Based on a Simulator Test. The Journal of Ergonomics, 5, 1000144.

[22] Qiao, F., Rahman, R., Li, Q. and Yu, L. (2016) Identifying Demographical Effects on Speed Patterns in Work Zones 
Using Smartphone Based Audio Warning Message System. Journal of Ergonomics. (in press)

[23] Li, Q., Qiao, F. and Yu, L. (2016) Vehicle Emission Implications of Drivers Smart Advisory System for Traffic Operations in Work Zones. Journal of Air \& Waste Management. (in press) http://dx.doi.org/10.1080/10962247.2016.1140095

[24] Li, Q., Qiao, F., Qiao, Y. and Yu, L. (2016) Implications of Smartphone Messages on Driving Performance along Local Streets. Proceedings of the 11th Asia Pacific Transportation Development Conference and 29th ICTPA Annual Conference-Bridging the East and West: Theories and Practices of Transportation in the Asia Pacific, Hsinchu, 27-29 May 2016.

[25] Chen, H., Cao, L. and Logan, D.B. (2011) Investigation into the Effect of an Intersection Crash Warning System on Driving Performance in a Simulator. Journal of Traffic Injury Prevention, 12, 529-537. http://dx.doi.org/10.1080/15389588.2011.603169

[26] Rahman, R., Qiao, F., Li, Q., Yu, L. and Kuo, P. (2015) Smart Phone Based Forward Collision Warning Messages in Work Zones to Enhance Safety and Reduce Emissions. Transportation Research Board 94th Annual Meeting, Washington DC, 11-15 January 2015, No. 15-0648.

[27] Derr, B.R. (2015) Evaluation of Change and Clearance Intervals Prior to the Flashing Yellow Arrow Permissive Left-Turn Indication, Project 03-125, NCHRP 03-125 [Anticipated] Federal Highway Administration, American Association of State Highway \& Transportation Officials, National Cooperative Highway Research Program, Transportation Research Board, Washington DC. RiP Project 39946.

[28] Tran, C., Bark, K. and Ng-Thow-Hing, V. (2013) A Left-Turn Driving Aid Using Projected Oncoming Vehicle Paths with Augmented Reality. Proceedings of the 5th International Conference on Automotive User Interfaces and Interactive Vehicular Applications, Eindhoven, 27-30 October 2013, 300-307. http://dx.doi.org/10.1145/2516540.2516581

[29] Dabbour, E. and Easa, S.M. (2009) Perceptual Framework for a Modern Left-Turn Collision Warning System. International Journal of Applied Science, Engineering and Technology, 5, 8-14.

[30] Lee, S.E., Knipling, R.R., DeHart, M.C., Perez, M.A., Holbrook, G.T., Brown, S.B., Stone, S.R. and Olson, R.L. (2004) Vehicle-Based Countermeasures for Signal and Stop Sign Violations: Task 1. Intersection Control Violation Crash Analyses Task 2. Top-Level System and Human Factors Requirements. Report No. DOT HS 809716 . Virginia Tech Transportation Institute, National Highway Traffic Safety Administration, Department of Transportation, Washington DC.

[31] White, B. and Eccles, K.A. (2002) Inexpensive, Infrastructure-Based, Intersection Collision. Avoidance System to Prevent Left-Turn Crashes with Opposite-Direction Traffic. Transportation Research Record: Journal of the Transportation Research Board, (No. 1800), Paper No. 02-3846.

[32] Pierowicz, J., Jocoy, E., Lloyd, M., Bittner, A. and Pirson, B. (2000) Intersection Collision Avoidance Using ITS Countermeasures. DOT HS 809171, US DOT National Highway Traffic Safety Administration, Office of Advanced Safety Research Washington DC, Contract No. DTNH22-93-C-07024.

[33] Najm, W.G., Koopmann, J., Smith, J.D. and Brewer, J. (2010) Frequency of Target Crashes for IntelliDrive Safety Systems. Report No. DOT HS 811381, National Highway Traffic Safety Administration, US DOT National Highway Traffic Safety Administration, Washington DC.

[34] NHTSA Promotes Two Connected-Car Technologies to Prevent Crashes (2014) Automotive FLEET, the Car and Truck Fleet and Leasing Management Magazine. http://www.automotive-fleet.com/news/story/2014/08/nhtsa-takes-steps-to-mandate-connected-car-technology.aspx

[35] United States Government Accountability Office (2013) Vehicle-to-Vehicle Technologies Expected to Offer Safety Benefits, but a Variety of Deployment Challenges Exist. GAO-14-13, Report to Congressional Requesters. http://www.gao.gov/assets/660/658709.pdf

[36] Woodhouse, K. (2012) Connected Vehicles: U-M Seeking 3,000 Ann Arbor Motorists for \$18M Wireless Project to Prevent Collisions. The Ann Arbor News. http://www.annarbor.com/news/university-of-michigan-seeking-3000-motorists-to-participate/

[37] Rosenthal, T.J., Chrstos, J.P., Aponso, B.L. and Allen, R.W. (2004) A Driving Simulator for Testing The Visibility and Conspicuity Of Highway Designs And Traffic Control Device Placement. Submitted in 2004 Transportation Research Board Annual Meeting, Washington DC, 11-15 January 2004.

[38] Manual on Traffic Control Device Specifications (MUTCD) 2009 Edition. http://mutcd.fhwa.dot.gov/htm/2009/part6/part6h.htm

[39] Listen—Convert Text to Speech (MP3) Online. http://ctrlq.org/listen/

[40] Garcia, R. (2014) Roadway Design Manual, Texas Department of Transportation.

[41] Vehicle Stopping Sight Distance Calculator. CGSNetwork.com. http://www.csgnetwork.com/stopdistcalc.html

[42] Friction and Co-Efficient of Friction. The Engineering Toolbox. http://www.engineeringtoolbox.com/friction-coefficients-d_778.html 